\section{Mini-Review}

Correspondence

Nicola R. Stanley-Wall

n.r.stanleywall@dundee.ac.uk

\title{
A pivotal role for the response regulator DegU in controlling multicellular behaviour
}

\author{
Ewan J. Murray, Taryn B. Kiley and Nicola R. Stanley-Wall \\ Division of Molecular and Environmental Microbiology, College of Life Sciences, MSI/WTB/JBC \\ Complex, University of Dundee, Dundee DD1 5EH, UK
}

\begin{abstract}
Bacteria control multicellular behavioural responses, including biofilm formation and swarming motility, by integrating environmental cues through a complex regulatory network. Heterogeneous gene expression within an otherwise isogenic cell population that allows for differentiation of cell fate is an intriguing phenomenon that adds to the complexity of multicellular behaviour. This review focuses on recent data about how DegU, a pleiotropic response regulator, co-ordinates multicellular behaviour in Bacillus subtilis. We review studies that challenge the conventional understanding of the molecular mechanisms underpinning the DegU regulatory system and others that describe novel targets of DegU during activation of biofilm formation by $B$. subtilis. We also discuss a novel role for DegU in regulating multicellular processes in the food-borne pathogen Listeria monocytogenes.
\end{abstract}

\section{Multicellular behaviour in single-celled prokaryotes}

It is easy to forget that when bacteria are grown in the laboratory the conditions used to generate such rapidly dividing free-living cells are very different from those in the natural environment. Most bacteria exist in their natural habitats as sessile multicellular communities called biofilms in which the bacterial population differentiates as part of the development process (Costerton et al., 1995; Vlamakis et al., 2008). That most bacterial species can live and grow within a shared habitat, and co-ordinate complex group behaviour that benefits the whole community, is still a relatively new concept (Shapiro, 1998). Examples of such behaviour leading to the propagation of bacterial spores include fruiting body formation in Myxococcus xanthus (Kaplan, 2003), biofilm formation and fruiting-body-like assembly in Bacillus subtilis (Branda et al., 2001) and aerial hyphae development in Streptomyces coelicolor (Claessen et al., 2006).

\section{Experimental advances provide insight into multicellular behaviour}

B. subtilis, like other bacterial species, is capable of manifesting different multicellular processes. Studies have focussed on understanding how this species is able to coordinate processes that include sporulation (Piggot \& Hilbert, 2004), the uptake of exogenous DNA (genetic competence) (Hamoen et al., 2003), social motility (swarming) (Kearns \& Losick, 2003), extracellular protease production (Dahl et al., 1992), and biofilm formation/ complex colony development (Branda et al., 2001; Hamon \& Lazazzera, 2001). Investigations on multicellular beha- viour in B. subtilis have advanced through three main approaches. First, investigations using 'wild' isolates led to the discovery that laboratory strains had lost their ability to express some of the multicellular behaviours described above (Branda et al., 2001; Kearns \& Losick, 2003; Stanley \& Lazazzera, 2005). B. subtilis laboratory isolates such as 168 (Spizizen, 1958) were derived from a progenitor strain that was treated with X-rays or chemical mutagens to make the cells more tractable (Srivatsan et al., 2008; Zeigler et al., 2008). The genes in which the mutations were introduced are now recognized as important for social behaviour and their identification helped to elucidate the genetic circuitry underpinning multicellular responses to the environment (Kearns \& Losick, 2003, 2005; Kearns et al., 2004; Stanley \& Lazazzera, 2005). Second, developments in the use of fluorescent reporter fusions enable gene expression to be monitored readily within the single cell by flow cytometry. Third, advances in microscopy techniques allow the detection of cell differentiation in an otherwise isogeneic bacterial population (Veening et al., 2004, 2005; Vlamakis et al., 2008).

\section{Co-ordination of multicellular behaviour processes by DegS-DegU}

Two-component signal transduction systems are the major family of signalling proteins by which bacteria sense and respond to changes in the environment. They typically consist of a membrane-associated histidine kinase (DegS) and a cytoplasmic response regulator (DegU). The former detects the signal or stress, whereas the latter controls cellular response, predominantly through gene transcription (Mascher et al., 2006). DegU plays a key role in 
regulating post-exponential-phase processes in B. subtilis, including activation and inhibition of genetic competence (Dubnau et al., 1994; Kunst et al., 1994; Ogura \& Tanaka, 1996), activation and inhibition of motility (Amati et al., 2004; Kobayashi, 2007; Verhamme et al., 2007), activation of degradative enzyme production (Dahl et al., 1992; Msadek et al., 1990), activation of poly- $\gamma$-glutamic acid production (Stanley \& Lazazzera, 2005) and also the activation and inhibition of biofilm formation (Kobayashi, 2007; Verhamme et al., 2007). DegU has regulatory activity in both its unphosphorylated and phosphorylated states. This initially led to its designation as a 'molecular switch' dependent on DegU phosphorylation by DegS (Dahl et al., 1992). However, recent studies using wild isolates of $B$. subtilis indicate that DegU P functions as a 'rheostat' that senses and responds to changes in the environment. This, in turn, enables the integration of genetic competence, swarming motility, biofilm formation and exoprotease production along an increasing gradient of DegU phosphorylation (Kobayashi, 2007; Verhamme et al., 2007).

\section{Mechanism of DegU and DegU P in response to signalling}

In its unphosphorylated state DegU activates genetic competence through the recruitment of ComK (Hamoen et al., 2000). ComK functions as an anti-repressor for the transcriptional repressors Rok and CodY, and thereby allows the expression of its own gene. This permits the establishment of the bistable system pre-required for competence development (Albano et al., 2005; Smits et al., 2007). In contrast, DegU P recruits RNA polymerase at promoter regions of genes such as $y v c A$ and aprE to activate biofilm formation and exoprotease production respectively (Ogura et al., 2003; Verhamme et al., 2007). Recent genome-wide transcription and proteomic studies have identified over 170 genes ( $\sim \%$ of the B. subtilis genome) that are regulated by $\mathrm{DegU} \sim \mathrm{P}$ under various growth conditions (Kobayashi, 2007; Mader et al., 2002; Ogura et al., 2001). Therefore the mechanism by which DegU P coordinates multicellular behaviour processes in response to signal perception is challenging. One simple model supported by in vitro data indicates that $\mathrm{DegU} \sim \mathrm{P}$ has specific affinities for different promoter regions. For example, the $f l g B$ promoter has a higher affinity for $\mathrm{DegU} \sim \mathrm{P}$ than the $s a c B$ promoter. This provides the molecular basis by which swarming motility could be activated prior to other multicellular processes (Kobayashi, 2007; Tsukahara \& Ogura, 2008). Variations in promoter binding affinities by transcription factors may represent a common mechanism mediating control over multicellular behaviour responses. High- and low-affinity binding sites in B. subtilis are used within the promoter regions of genes controlled by Spo0A. At low levels of Spo0A phosphorylation, biofilm formation and cannibalism are regulated. In contrast, the activation of sporulation occurs at high levels of Spo0A phosphorylation (Fujita et al., 2005). However, the question arises: Why does a process that is activated at lower levels of signal perception not occur in the presence of a high level of the signal? The first possibility is that when low-affinity promoters are triggered, a negative feedback loop blocks the process that is controlled by the high-affinity promoters. Second, the promoter regions contain multiple binding sites, with specific affinities, that result in the activation of transcription at low levels of signal perception but inhibition of transcription at high levels of signal. Third, multiple environmental conditions need to be sensed and integrated by the cell to activate a physiological response.

\section{A three-tiered regulatory system controls DegS- DegU activity}

Given the central role that DegS and DegU have in coordinating multicellular responses in B. subtilis it is not surprising that the DegS-DegU regulatory system is finely controlled at the following three stages within the cell: $\operatorname{deg} U$ transcription, DegU phosphorylation and $\mathrm{DegU} \sim \mathrm{P}$ activity.

\section{degU transcription}

The degSU operon contains three promoters (Veening et al., 2008a; Yasumura et al., 2008). The first is upstream of $\operatorname{deg} S$ and drives the expression of $\operatorname{deg} S$ and $\operatorname{deg} U$. The second is located within the coding region of $\operatorname{deg} S$ and increases the level of $\operatorname{deg} U$ under nitrogen-limiting conditions. The third is located in the degS- $\operatorname{deg} U$ intergenic region and increases the level of $\operatorname{deg} U$ in response to DegU P. In laboratory isolates, the positive auto-regulation of $\operatorname{deg} U$ transcription (Fig. 1) by $\operatorname{DegU} \sim \mathrm{P}$ leads to the heterogeneous expression of $\operatorname{deg} U$ within the population (Veening et al., 2008a, b).

\section{DegU phosphorylation}

DegS is a cytoplasmic bifunctional protein that exhibits kinase and phosphatase activities (Tanaka et al., 1991). DegS interacts with the SMC-ScpA-ScpB complex, which controls DNA condensation and repair. The interaction of DegS with ScpA inhibits its kinase activity and results in a decrease in the pool of DegU P within the cell. As the level of SMC-ScpA-ScpB complex decreases during stationary phase there is an increase in the level of $\operatorname{DegU} \sim \mathrm{P}$ in that growth phase (Dervyn et al., 2004). Transfer of the phosphate moiety from DegS to DegU (Fig. 1) is enhanced in the presence of DegQ, a small protein of 46 amino acids (Kobayashi, 2007). Some laboratory isolates of B. subtilis contain a point mutation within the promoter of $\operatorname{deg} Q$ that reduces the level of DegQ synthesized (Stanley \& Lazazzera, 2005); this in turn, reduces the level of DegU P in the cell (Kobayashi, 2007; Stanley \& Lazazzera, 2005; Verhamme et al., 2007). This single point mutation highlights one of the key genomic differences between wild and laboratory isolates of B. subtilis that influences multicellular behaviour (Kearns et al., 2004; Kobayashi, 2008; Stanley \& Lazazzera, 2005). Transcription of $\operatorname{deg} Q$ is regulated by the quorumsensing-responsive transcription factor ComA (Msadek et al., 1991). This ensures that DegU P in the cell increases alongside an increase in cell density and is maximal at 


\section{OUTSIDE}
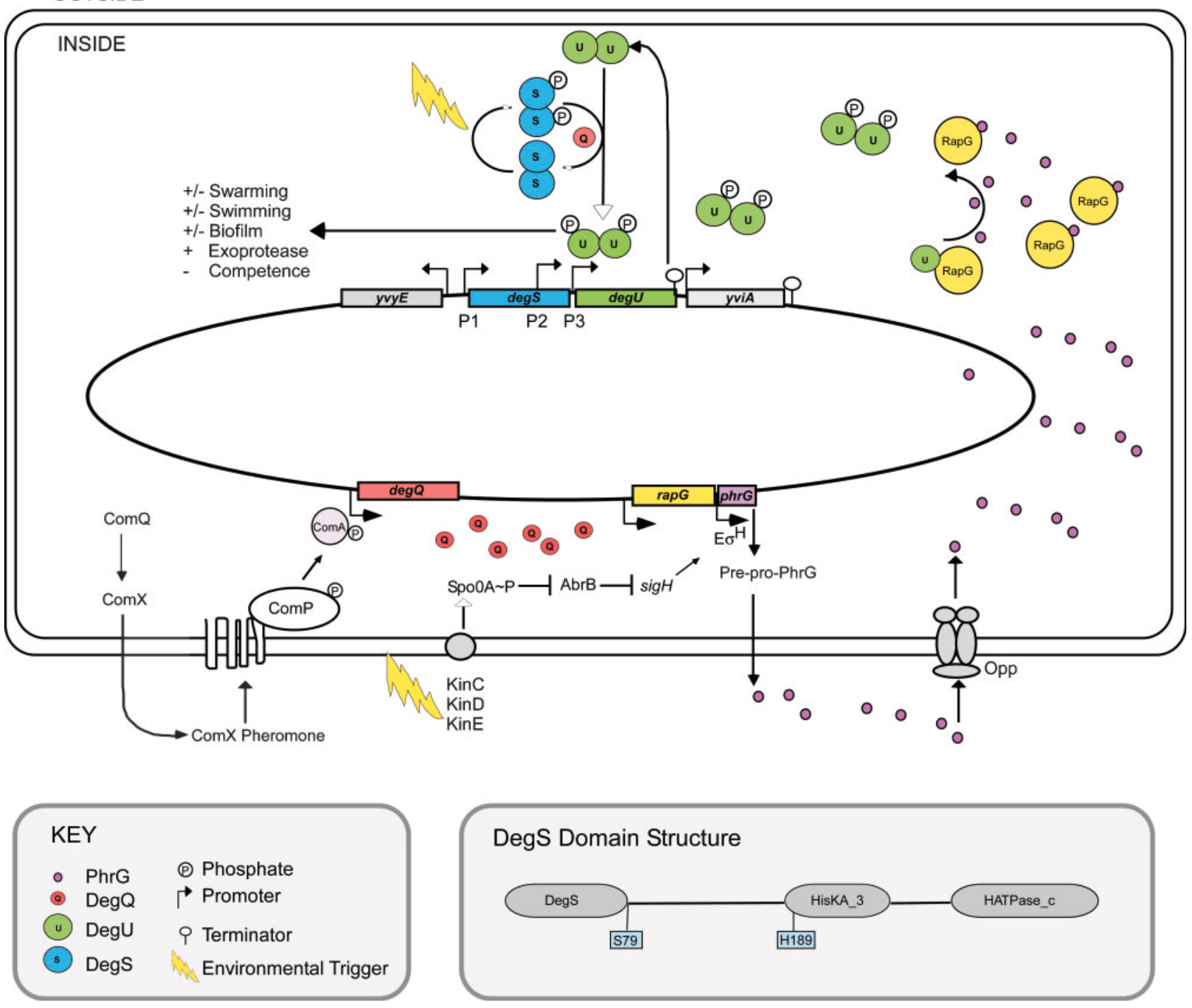

Fig. 1. The DegS-DegU regulatory system of $B$. subtilis. The names of the genes are indicated. Open arrowheads indicate a change in the phosphorylation state. The lower left-hand insert provides a symbol key and the lower right-hand insert depicts the domain structure of DegS, with the HisKA_3 and HATPase_c domains identified by Pfam shown in grey. S79 represents serine amino acid number 79; $\mathrm{H} 189$ represents the site of autophosphorylation on histidine 189. '+' represents activation and '-' represents inhibition.

stationary phase. DegQ does not affect the stability of DegS P or block the intrinsic phosphatase action of DegS (Kobayashi, 2007); therefore the mechanism by which DegS controls the balance of phosphatase and kinase activity remains unknown.

\section{DegU P activity}

The response regulator aspartyl phosphatase (Rap) RapG binds to DegU, without affecting the latter's phosphorylation status. This suggests that RapG inhibits the ability of DegU to bind to target promoter DNA (Ogura et al., 2003). RapG is encoded in an operon with PhrG, a phosphatase regulator (Phr). Although rapG and $p h r G$ share a common promoter upstream of rapG, the transcription of $p h r G$ is also activated by a $\sigma^{\mathrm{H}}$-dependent promoter on entry to stationary phase (Britton et al., 2002). At high levels of PhrG production, PhrG interacts with RapG, lessening RapG inhibition of DegU activity. As the RapG-PhrG system functions as a quorum-sensing system (Fig. 1), DegU P activity increases in parallel with an increase in cell density (Lazazzera et al., 1999; Ogura et al., 2003).

\section{New roles for DegU activity in B. subtilis during biofilm formation}

DegU was first identified as a positive regulator of biofilm formation in a study using $B$. subtilis isolate RO-FF1 
(Stanley \& Lazazzera, 2005). Currently, three targets that are activated by $\mathrm{DegU} \sim \mathrm{P}$ are known. The first is poly- $\gamma$ glutamic acid, an extracellular polymer that can form part of the extracellular matrix of some isolates of B. subtilis, though not in NCIB 3610 (Branda et al., 2006; Morikawa et al., 2006; Stanley \& Lazazzera, 2005). This suggests that the specific requirements to form a multicellular community differ in a strain-dependent manner and highlights the value of scrutinizing different natural isolates. The other two targets for DegU are the proteins, YuaB and YvcA. YuaB is a small secreted protein required for pellicle formation and complex colony development in ATCC 6051 and NCIB 3610 (Kobayashi, 2007; Verhamme et al., 2008). YvcA is a putative membrane-bound lipoprotein required for complex colony development in NCIB 3610 but not for pellicle formation in ATCC 6051 (Kobayashi, 2007; Verhamme et al., 2007). A complex genetic circuit that is dependent on activation of $\operatorname{DegU}$ and Spo0A ensuring $y v c A$ and $y u a B$ transcription during complex colony development in B. subtilis NCIB 3610 has recently been described (Verhamme et al., 2008).

\section{Heterogeneous $\operatorname{deg} U$ expression and exoprotease production}

During biofilm formation by B. subtilis, cells differentiate into specific subpopulations that become responsible for matrix production or sporulation (Chai et al., 2008; Vlamakis et al., 2008). This finding suggests that biofilm matrix production altruistically benefits the entire population/community, not just the producer cells. During heterogeneous gene expression, threshold levels of a key regulator controlling cell state need to be attained. This can be mediated by a positive feedback loop at the transcription stage (Losick \& Desplan, 2008). Intriguingly it was recently reported that while $\operatorname{deg} U$ transcription is auto-activated it is not sufficient to generate heterogeneous expression in wildtype laboratory isolates. However, when genetic manipulations are used to increase the level of DegU P, a distinct bistable population was observed (Veening et al., 2008a). In the same study it also was demonstrated that a small population of cells in which aprE, the gene encoding the major exoprotease of $B$. subtilis, is copiously transcribed can be established (Veening et al., 2008a). Two criteria must be met for this to happen in the small subset of cells. First, Spo0A P levels must increase to a threshold that stimulates derepression of aprE transcription (but not to such a level that the cells sporulate). Second, the levels of DegU P in the cell must be high. This dual requirement of DegU and Spo0A activation as part of a genetic logic-AND network might represent a common mechanism for co-ordinating entry into the different multicellular behavioural processes of B. subtilis (Veening et al., 2008a, b; Verhamme et al., 2008). It remains to be seen whether intracellular fluctuations of phosphorylated DegU and Spo0A combined with intrinsic differences in promoter binding affinities coordinate the different multicellular behavioural processes manifested by B. subtilis.

\section{Motility and biofilm formation regulation by DegU in L. monocytogenes}

The role of DegU in co-ordinating multicellular behaviour is not restricted to B. subtilis. Listeria monocytogenes is a Gram-positive facultative intracellular pathogen that causes listeriosis. DegU (encoded by lmo2515) regulates motility, biofilm formation and virulence in Listeria species (Gueriri et al., 2008b; Knudsen et al., 2004; Williams et al., 2005a, b). The genome sequences of the pathogenic strain L. monocytogenes EGD-e and nonpathogenic strain $L$. innocua are remarkably similar to that of B. subtilis (Glaser et al., 2001). However, in the region surrounding $\operatorname{deg} U$, the $\operatorname{deg} S$ homologue is conspicuously absent despite other major genome features being maintained (Gueriri et al., 2008b; Knudsen et al., 2004). The absence of degS appears to be specific to the Listeria species (Fig. 2), although further evolutionary analyses are needed to establish whether $\operatorname{deg} S$ has been lost from Listeria or gained by Bacillus (Gueriri et al., 2008b).

Biofilm formation by L. monocytogenes is dependent on flagellar motility to propel the cells towards a surface prior to attachment (Lemon et al., 2007). DegU was recently identified as a positive activator of flagellum biosynthesis (Knudsen et al., 2004; Williams et al., 2005a, b). When grown at $\leqslant 30{ }^{\circ} \mathrm{C} \mathrm{L}$. monocytogenes has four to six simple peritrichous glycosylated flagella. The flagellum is glycosylated at multiple sites on the flagellin protein FlaA, with up to six glycosylation moieties per monomer. The glycosylation moiety is transferred to FlaA post-translationally by the bifunctional O-GlcNAc transferase GmaR (Shen et al., 2006). The physiological significance of the glycosylation is not yet fully understood but it is proposed that it may be an important factor for environmental adaptation outside the host. At temperatures $\geqslant 37^{\circ} \mathrm{C} L$. monocytogenes is typically non-motile. Inhibition of motility at high temperatures occurs through the tightly controlled repression of flaA transcription by the protein $\mathrm{MogR}$, which binds to the $f l a A$ upstream promoter region (Shen \& Higgins, 2006). It was initially proposed that DegU served as a direct activator of flaA transcription at low temperature, although later work showed that this role is indirect (Shen \& Higgins, 2006). At low temperatures DegU activates transcription of $g m a R$, which encodes GmaR, the transcriptional activator of flaA. How DegU activates gmaR transcription at low temperatures but not at high temperatures remains unknown. GmaR is a bifunctional protein that first binds to MogR, removes it from the flaA promoter, and then glycosylates the FlaA protein. DegU also controls flagellin levels post-transcription, as transcription of $f l a A$ in a $\operatorname{mog} R \operatorname{deg} U$ strain background per se is not sufficient to restore motility (Shen \& Higgins, 2006). This unique regulatory mechanism ensures that flagella of L. monocytogenes are only synthesized at low temperatures and that the flagella are fully glycosylated. 


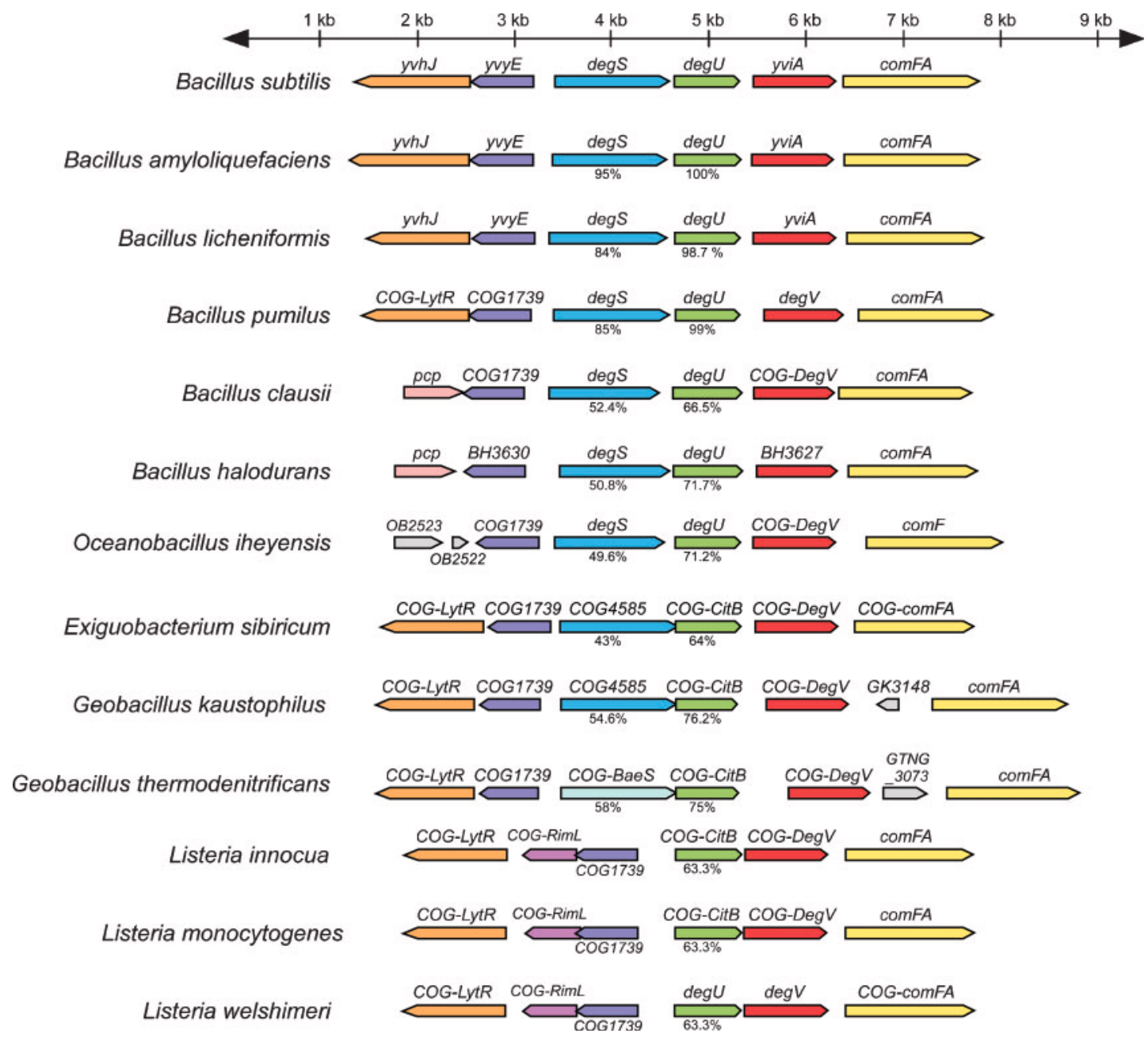

Fig. 2. Genome context of degU on the chromosome of B. subtilis with respect to other Gram-positive bacteria. The percentage identity at the protein level is indicated for $\operatorname{deg} U$ and $\operatorname{deg} S$ homologues under the gene. The gene size, position and direction are drawn to the scale indicated at the top of the diagram.

\section{DegU regulates virulence in $L$. monocytogenes}

Although the mechanism for DegU-dependent motility is relatively well known, how DegU affects virulence is not yet understood. DegU mutant strains are still able to enter host cells with an efficiency that is comparable to, or even better than, that of wild-type cells (Williams et al., 2005a). However, the bacterial load maintained within the spleen and other organs of the host is lower (Knudsen et al., 2004). DegU-dependent control of virulence is not due to the non-motile phenotype because flagella-minus strains of $L$. monocytogenes remain virulent (Shen \& Higgins, 2006). It will be exciting to understand how DegU contributes to virulence and how this is co-ordinated with its other roles in controlling motility and activation of biofilm formation (Gueriri et al., 2008b).

\section{DegU is an orphan response regulator in L. monocytogenes}

The absence of $\operatorname{deg} S$ in L. monocytogenes raises questions about whether DegU can be phosphorylated, and if so, whether DegU P is required to activate flagella-based motility and/or virulence. Although DegU is an orphan response regulator in L. monocytogenes, importantly there are no orphan sensor kinases encoded in its genome (Williams et al., 2005a). It is possible that in the absence of a cognate or orphan sensor kinase, DegU could be phosphorylated by a non-cognate sensor kinase. However, this is very unlikely due to the inbuilt specificity mechanisms in a two-component regulatory system (Laub \& Goulian, 2007). Alternatively, phosphorylation of DegU could be mediated via a small molecular phosphate donor such as acetyl phosphate. This is becoming increasingly 
recognized as a global regulator of gene transcription (Wolfe et al., 2003, 2008). The presence of an 'orphan' response regulator, or sensor kinase that also has phosphatase activity, suggests that acetyl phosphate may play a role in the signal transduction system (Wolfe, 2005). A study on motility and ethanol resistance by $L$. monocytogenes investigated whether DegU is required to be phosphorylated in order to carry out its regulatory function (Mauder et al., 2008). These authors constructed a strain of L. monocytogenes carrying a variant of $\operatorname{deg} U$ with a point mutation in the proposed phosphorylation site. They demonstrated a partial restoration of swimming motility in comparison with the $\operatorname{deg} U$ mutant, though motility was less than that observed in the wild-type. These findings indicate that DegU retains some functionality in its unphosphorylated state, but do not rule out the possibility that $\operatorname{DegU} \sim \mathrm{P}$ has some physiological role. Consistent with this suggestion, DegU of L. monocytogenes can be phosphorylated by acetyl phosphate in vitro and alterations in the level of acetyl phosphate in vivo control motility and biofilm formation (Gueriri et al., 2008a). As the level of acetyl phosphate varies with both growth condition and growth phase (Klein et al., 2007; Wolfe, 2005) it is possible that DegU functions as a read-out of the metabolic status of L. monocytogenes.

\section{Future studies}

Since the advent of single-cell analyses and the observation of multicellular behaviour, the full potential of DegU as a central regulator in both $L$. monocytogenes and $B$. subtilis is becoming apparent. There remain many unanswered questions about how DegU functions in both Bacillus and Listeria species. A recent phosphoproteome screening of $B$. subtilis found that DegS can be phosphorylated on amino acid serine 79. This is outside the HisKA_3 domain containing histidine 189, which is the site (Fig. 1) of autophosphorylation (Macek et al., 2007). This raises questions about whether phosphorylation on serine 79 has any physiological role in $B$. subtilis. For example, is the phosphorylation of serine 79 and histidine 189 responsible for controlling separate multicellular behaviour processes that are dependent on DegU P in the face of different environmental stimuli? Additionally, growing evidence indicates that the function of $\mathrm{DegU}$ in laboratory isolates differs from that of wild isolates of B. subtilis (Kobayashi, 2007; Stanley \& Lazazzera, 2005; Veening et al., 2008a; Verhamme et al., 2007). Therefore it remains to be established whether heterogeneous expression of $\operatorname{deg} U$ occurs in wild isolates (e.g. NCIB 3160) of B. subtilis. If heterogeneous expression is observed, what influence does this have over the capacity to integrate multicellular behaviour responses? For L. monocytogenes, which lacks $\operatorname{degS}$, it is important to establish whether a heterogeneous population dependent on DegU can be formed. If so, does the differentiation of tasks within the cell population confer any survival advantage to the bacterium both within and outside the host?

\section{Concluding remarks}

It is likely that the DegS-DegU regulatory system will continue to provide an excellent model of a 'systems biology' approach. Thus objectives will be to understand how bacteria co-ordinate the decision-making processes that occur within the cell to ensure that the desired physiological response occurs in the face of different environmental conditions. Our ability to study multicellular behaviour in B. subtilis, and other closely related species, will be enhanced upon completion of genome sequences of natural isolates collected from a variety of geographical locations (http://www.bacillusgenomics.org/ bsubtilis/index.html) (Earl et al., 2007, 2008; Srivatsan et al., 2008). Such data could be used to determine the impacts of genome polymorphisms on behaviour and adaptation.

\section{Acknowledgements}

This work was supported by the Biotechnology and Biological Sciences Research Council (grant number BB/C520404/1, BB/ E001572/1). We thank Professor Frank Sargent for helpful discussions and Professor Geoff Gadd for a critical assessment of the manuscript. We are grateful to the two anonymous reviewers and Dr Alisdair McLean for their expert comments, which significantly helped to improve the manuscript.

\section{References}

Albano, M., Smits, W. K., Ho, L. T., Kraigher, B., Mandic-Mulec, I., Kuipers, O. P. \& Dubnau, D. (2005). The Rok protein of Bacillus subtilis represses genes for cell surface and extracellular functions. $J$ Bacteriol 187, 2010-2019.

Amati, G., Bisicchia, P. \& Galizzi, A. (2004). DegU-P represses expression of the motility fla-che operon in Bacillus subtilis. J Bacteriol 186, 6003-6014.

Branda, S. S., Gonzalez-Pastor, J. E., Ben-Yehuda, S., Losick, R. \& Kolter, R. (2001a). Fruiting body formation by Bacillus subtilis. Proc Natl Acad Sci U S A 98, 11621-11626.

Branda, S. S., Chu, F., Kearns, D. B., Losick, R. \& Kolter, R. (2006). A major protein component of the Bacillus subtilis biofilm matrix. Mol Microbiol 59, 1229-1238.

Britton, R. A., Eichenberger, P., Gonzalez-Pastor, J. E., Fawcett, P., Monson, R., Losick, R. \& Grossman, A. D. (2002). Genome-wide analysis of the stationary-phase sigma factor (Sigma-H) regulon of Bacillus subtilis. J Bacteriol 184, 4881-4890.

Chai, Y., Chu, F., Kolter, R. \& Losick, R. (2008). Bistability and biofilm formation in Bacillus subtilis. Mol Microbiol 67, 254-263.

Claessen, D., de Jong, W., Dijkhuizen, L. \& Wosten, H. A. (2006). Regulation of Streptomyces development: reach for the sky! Trends Microbiol 14, 313-319.

Costerton, J. W., Lewandowski, Z., Caldwell, D. E., Korber, D. R. \& Lappin-Scott, H. M. (1995). Microbial biofilms. Annu Rev Microbiol 49, 711-745.

Dahl, M. K., Msadek, T., Kunst, F. \& Rapoport, G. (1992). The phosphorylation state of the DegU response regulator acts as a molecular switch allowing either degradative enzyme synthesis or expression of genetic competence in Bacillus subtilis. J Biol Chem 267, 14509-14514. 
Dervyn, E., Noirot-Gros, M. F., Mervelet, P., McGovern, S., Ehrlich, S. D., Polard, P. \& Noirot, P. (2004). The bacterial condensin/cohesinlike protein complex acts in DNA repair and regulation of gene expression. Mol Microbiol 51, 1629-1640.

Dubnau, D., Hahn, J., Roggiani, M., Piazza, F. \& Weinrauch, Y. (1994). Two-component regulators and genetic competence in Bacillus subtilis. Res Microbiol 145, 403-411.

Earl, A. M., Losick, R. \& Kolter, R. (2007). Bacillus subtilis genome diversity. J Bacteriol 189, 1163-1170.

Earl, A. M., Losick, R. \& Kolter, R. (2008). Ecology and genomics of Bacillus subtilis. Trends Microbiol 16, 269-275.

Fujita, M., Gonzalez-Pastor, J. E. \& Losick, R. (2005). High- and lowthreshold genes in the Spo0A regulon of Bacillus subtilis. J Bacteriol 187, 1357-1368.

Glaser, P., Frangeul, L., Buchrieser, C., Rusniok, C., Amend, A., Baquero, F., Berche, P., Bloecker, H., Brandt, P. \& other authors (2001). Comparative genomics of Listeria species. Science 294, 849852.

Gueriri, I., Bay, S., Dubrac, S., Cyncynatus, C. \& Msadek, T. (2008a). The Pta-AckA pathway controlling acetyl phosphate levels and the phosphorylation state of the DegU orphan response regulator both play a role in regulating Listeria monocytogenes motility and chemotaxis. Mol Microbiol, doi:10.1111/j.1365-2958.2008.06496.x.

Gueriri, I., Cyncynatus, C., Dubrac, S., Arana, A. T., Dussurget, O. \& Msadek, T. (2008b). The DegU orphan response regulator of Listeria monocytogenes autorepresses its own synthesis and is required for bacterial motility, virulence and biofilm formation. Microbiology 154, 2251-2264.

Hamoen, L. W., Van Werkhoven, A. F., Venema, G. \& Dubnau, D. (2000). The pleiotropic response regulator DegU functions as a priming protein in competence development in Bacillus subtilis. Proc Natl Acad Sci U S A 97, 9246-9251.

Hamoen, L. W., Venema, G. \& Kuipers, O. P. (2003). Controlling competence in Bacillus subtilis: shared use of regulators. Microbiology 149, 9-17.

Hamon, M. A. \& Lazazzera, B. A. (2001). The sporulation transcription factor Spo0A is required for biofilm development in Bacillus subtilis. Mol Microbiol 42, 1199-1209.

Kaplan, H. B. (2003). Multicellular development and gliding motility in Myxococcus xanthus. Curr Opin Microbiol 6, 572-577.

Kearns, D. B. \& Losick, R. (2003). Swarming motility in undomesticated Bacillus subtilis. Mol Microbiol 49, 581-590.

Kearns, D. B. \& Losick, R. (2005). Cell population heterogeneity during growth of Bacillus subtilis. Genes Dev 19, 3083-3094.

Kearns, D. B., Chu, F., Rudner, R. \& Losick, R. (2004). Genes governing swarming in Bacillus subtilis and evidence for a phase variation mechanism controlling surface motility. Mol Microbiol 52, 357-369.

Klein, A. H., Shulla, A., Reimann, S. A., Keating, D. H. \& Wolfe, A. J. (2007). The intracellular concentration of acetyl phosphate in Escherichia coli is sufficient for direct phosphorylation of twocomponent response regulators. J Bacteriol 189, 5574-5581.

Knudsen, G. M., Olsen, J. E. \& Dons, L. (2004). Characterization of DegU, a response regulator in Listeria monocytogenes, involved in regulation of motility and contributes to virulence. FEMS Microbiol Lett 240, 171-179.

Kobayashi, K. (2007). Gradual activation of the response regulator DegU controls serial expression of genes for flagellum formation and biofilm formation in Bacillus subtilis. Mol Microbiol 66, 395-409.

Kobayashi, K. (2008). SlrR/SlrA control the initiation of biofilm formation in Bacillus subtilis. Mol Microbiol 69, 1399-1410.
Kunst, F., Msadek, T., Bignon, J. \& Rapoport, G. (1994). The DegS/ DegU and ComP/ComA two-component systems are part of a network controlling degradative enzyme synthesis and competence in Bacillus subtilis. Res Microbiol 145, 393-402.

Laub, M. T. \& Goulian, M. (2007). Specificity in two-component signal transduction pathways. Annu Rev Genet 41, 121-145.

Lazazzera, B. A., Palmer, T., Quisel, J. D. \& Grossman, A. D. (1999). Cell density control of gene expression and development in Bacillus subtilis. In Cell-Cell Signaling in Bacteria, pp. 27-46. Edited by G. M. Dunny \& S. C. Winas. Washington, DC: American Society for Microbiology.

Lemon, K. P., Higgins, D. E. \& Kolter, R. (2007). Flagellar motility is critical for Listeria monocytogenes biofilm formation. J Bacteriol 189, 4418-4424.

Losick, R. \& Desplan, C. (2008). Stochasticity and cell fate. Science 320, 65-68.

Macek, B., Mijakovic, I., Olsen, J. V., Gnad, F., Kumar, C., Jensen, P. R. \& Mann, M. (2007). The serine/threonine/tyrosine phosphoproteome of the model bacterium Bacillus subtilis. Mol Cell Proteomics 6, 697-707.

Mader, U., Antelmann, H., Buder, T., Dahl, M. K., Hecker, M. \& Homuth, G. (2002). Bacillus subtilis functional genomics: genomewide analysis of the DegS-DegU regulon by transcriptomics and proteomics. Mol Genet Genomics 268, 455-467.

Mascher, T., Helmann, J. D. \& Unden, G. (2006). Stimulus perception in bacterial signal-transducing histidine kinases. Microbiol Mol Biol Rev 70, 910-938.

Mauder, N., Williams, T., Fritsch, F., Kuhn, M. \& Beier, D. (2008). Response regulator DegU of Listeria monocytogenes controls temperature-responsive flagellar gene expression in its unphosphorylated state. J Bacteriol 190, 4777-4781.

Morikawa, M., Kagihiro, S., Haruki, M., Takano, K., Branda, S., Kolter, R. \& Kanaya, S. (2006). Biofilm formation by a Bacillus subtilis strain that produces $\gamma$-polyglutamate. Microbiology 152, 2801-2807.

Msadek, T., Kunst, F., Henner, D., Klier, A., Rapoport, G. \& Dedonder, R. (1990). Signal transduction pathway controlling synthesis of a class of degradative enzymes in Bacillus subtilis: expression of the regulatory genes and analysis of mutations in $\mathrm{degS}$ and $\operatorname{deg} U$. J Bacteriol 172, 824-834.

Msadek, T., Kunst, F., Klier, A. \& Rapoport, G. (1991). DegS-DegU and ComP-ComA modulator-effector pairs control expression of the Bacillus subtilis pleiotropic regulatory gene degQ. J Bacteriol 173, 2366-2377.

Ogura, M. \& Tanaka, T. (1996). Bacillus subtilis DegU acts as a positive regulator for comK expression. FEBS Lett 397, 173-176.

Ogura, M., Yamaguchi, H., Yoshida, K., Fujita, Y. \& Tanaka, T. (2001). DNA microarray analysis of Bacillus subtilis DegU, ComA and PhoP regulons: an approach to comprehensive analysis of B. subtilis twocomponent regulatory systems. Nucleic Acids Res 29, 3804-3813.

Ogura, M., Shimane, K., Asai, K., Ogasawara, N. \& Tanaka, T. (2003). Binding of response regulator DegU to the aprE promoter is inhibited by RapG, which is counteracted by extracellular PhrG in Bacillus subtilis. Mol Microbiol 49, 1685-1697.

Piggot, P. J. \& Hilbert, D. W. (2004). Sporulation of Bacillus subtilis. Curr Opin Microbiol 7, 579-586.

Shapiro, J. A. (1998). Thinking about bacterial populations as multicellular organisms. Annu Rev Microbiol 52, 81-104.

Shen, A. \& Higgins, D. E. (2006). The MogR transcriptional repressor regulates nonhierarchal expression of flagellar motility genes and virulence in Listeria monocytogenes. PLoS Pathog 2, e30.

Shen, A., Kamp, H. D., Grundling, A. \& Higgins, D. E. (2006). A bifunctional $O$-GlcNAc transferase governs flagellar motility through anti-repression. Genes Dev 20, 3283-3295. 
Smits, W. K., Hoa, T. T., Hamoen, L. W., Kuipers, O. P. \& Dubnau, D. (2007). Antirepression as a second mechanism of transcriptional activation by a minor groove binding protein. Mol Microbiol 64, 368-381.

Spizizen, J. (1958). Transformation of biochemically deficient strains of Bacillus subtilis by deoxyribonucleate. Proc Natl Acad Sci U S A 44, 1072-1078.

Srivatsan, A., Han, Y., Peng, J., Tehranchi, A. K., Gibbs, R., Wang, J. D. \& Chen, R. (2008). High-precision, whole-genome sequencing of laboratory strains facilitates genetic studies. PLoS Genet 4, e1000139.

Stanley, N. R. \& Lazazzera, B. A. (2005). Defining the genetic differences between wild and domestic strains of Bacillus subtilis that affect poly- $\gamma$-DL-glutamic acid production and biofilm formation. $\mathrm{Mol}$ Microbiol 57, 1143-1158.

Tanaka, T., Kawata, M. \& Mukai, K. (1991). Altered phosphorylation of Bacillus subtilis DegU caused by single amino acid changes in DegS. J Bacteriol 173, 5507-5515.

Tsukahara, K. \& Ogura, M. (2008). Promoter selectivity of the Bacillus subtilis response regulator $\mathrm{DegU}$, a positive regulator of the fla/che operon and sacB. BMC Microbiol 8, 8.

Veening, J. W., Smits, W. K., Hamoen, L. W., Jongbloed, J. D. \& Kuipers, O. P. (2004). Visualization of differential gene expression by improved cyan fluorescent protein and yellow fluorescent protein production in Bacillus subtilis. Appl Environ Microbiol 70, 6809-6815.

Veening, J. W., Hamoen, L. W. \& Kuipers, O. P. (2005). Phosphatases modulate the bistable sporulation gene expression pattern in Bacillus subtilis. Mol Microbiol 56, 1481-1494.

Veening, J. W., Igoshin, O. A., Eijlander, R. T., Nijland, R., Hamoen, L. W. \& Kuipers, O. P. (2008a). Transient heterogeneity in extracellular protease production by Bacillus subtilis. Mol Syst Biol 4, 184.

Veening, J. W., Smits, W. K. \& Kuipers, O. P. (2008b). Bistability, epigenetics, and bet-hedging in Bacteria. Annu Rev Microbiol 62, 193-210.
Verhamme, D. T., Kiley, T. B. \& Stanley-Wall, N. R. (2007). DegU coordinates multicellular behaviour exhibited by Bacillus subtilis. Mol Microbiol 65, 554-568.

Verhamme, D. T., Murray, E. J. \& Stanley-Wall, N. R. (2008). DegU and Spo0A jointly control transcription of two loci required for complex colony development by Bacillus subtilis. J Bacteriol, Oct 31 [Epub ahead of print]

Vlamakis, H., Aguilar, C., Losick, R. \& Kolter, R. (2008). Control of cell fate by the formation of an architecturally complex bacterial community. Genes Dev 22, 945-953.

Williams, T., Bauer, S., Beier, D. \& Kuhn, M. (2005a). Construction and characterization of Listeria monocytogenes mutants with in-frame deletions in the response regulator genes identified in the genome sequence. Infect Immun 73, 3152-3159.

Williams, T., Joseph, B., Beier, D., Goebel, W. \& Kuhn, M. (2005b). Response regulator DegU of Listeria monocytogenes regulates the expression of flagella-specific genes. FEMS Microbiol Lett 252, 287298.

Wolfe, A. J. (2005). The acetate switch. Microbiol Mol Biol Rev 69, 1250 .

Wolfe, A. J., Chang, D. E., Walker, J. D., Seitz-Partridge, J. E., Vidaurri, M. D., Lange, C. F., Prüss, B. M., Henk, M. C., Larkin, J. C. \& Conway, T. (2003). Evidence that acetyl phosphate functions as a global signal during biofilm development. Mol Microbiol 48, 977-988.

Wolfe, A. J., Parikh, N., Lima, B. P. \& Zemaitaitis, B. (2008). Signal integration by the two-component signal transduction response regulator CpxR. J Bacteriol 190, 2314-2322.

Yasumura, A., Abe, S. \& Tanaka, T. (2008). Involvement of nitrogen regulation in Bacillus subtilis degU expression. J Bacteriol 190, 51625171.

Zeigler, D. R., Pragai, Z., Rodriguez, S., Chevreux, B., Muffler, A., Albert, T., Bai, R., Wyss, M. \& Perkins, J. B. (2008). The origins of 168, W23, and other Bacillus subtilis legacy strains. J Bacteriol 190, 69836995. 